\title{
Exomphalos Major in Adults: A Treatment Modality
}

\author{
${ }^{1}$ Tanweerul Huda, ${ }^{2}$ Ashok Mhaske
}

\begin{abstract}
Omphalocele $(\mathrm{OC})$ is a congenital abdominal wall defect (CAWD) at the site of the umbilical ring with evisceration of the bowel covered by a three-layered membrane of peritoneum, Wharton's jelly, and amnion. It is associated with an underdeveloped abdominal cavity and a high degree of viscera abdominal disproportion. An adult female giant OC patient was treated at our hospital using the component separation technique (CST) after reviewing different standard techniques. No evidence of any compartment syndrome or ventral hernia was detected postoperatively. Giant OC in an adult healed in the same way using CST as in an infant with favorable outcomes.
\end{abstract}

Keywords: Exomphalos, Exomphalos major, Giant omphalocele. Omphalocele,

How to cite this article: Huda T, Mhaske A. Exomphalos Major in Adults: A Treatment Modality. Int J Recent Surg Med Sci 2016;2(2):66-69.

\section{Source of support: Nil}

Conflict of interest: None

\section{INTRODUCTION}

Omphalocele (OC) is a congenital abdominal wall defect (CAWD) at the site of the umbilical ring with evisceration of the bowel covered by a three-layered membrane of peritoneum, Wharton's jelly, and amnion. It is associated with other congenital anomalies in up to $77 \%$ of patients. Omphalocele can be approximately divided into two groups: Minor and major (giant). In minor OC, the abdominal wall defect is relatively small $(\leq 4 \mathrm{~cm})$ and can be generally managed by primary closure. Giant OC is defined as abdominal wall defect of at least $5 \mathrm{~cm}$ and liver included. ${ }^{1-4}$

Omphalocele occurs in 2.5/10,000 births and is associated with a high rate of mortality (25\%) and severe malformations, such as cardiac anomalies (50\%) and neural tube defect (40\%). Male-to-female ratio is 1.5:1.

It is associated with an underdeveloped abdominal cavity and a high degree of viscera abdominal

\footnotetext{
${ }^{1}$ Assistant Professor, ${ }^{2}$ Professor

${ }^{1,2}$ Department of General Surgery, Peoples College of Medical Sciences and Research Centre, Bhopal, Madhya Pradesh, India

Corresponding Author: Ashok Mhaske, Professor, Department of General Surgery, Peoples College of Medical Sciences and Research Centre, Bhopal, Madhya Pradesh, India, Phone: +919669111110, e-mail: drmhaske4321@gmail.com
}

disproportion that prohibits save primary closure. Primary closure is often impossible and may lead to hypotension, decreased cardiac output, and respiratory failure. ${ }^{5}$ Operative treatments described in the literature are bridging the defect with dura mater, alloderm grafts, silo prostheses, skin flaps, prosthetic meshes, two bipedicled flaps, the use of tissue expanders, delayed staged repair, ${ }^{3,6-14}$ and component separation technique (CST). The CST is based on enlargement of the abdominal wall surface by translation of the muscular layers without compromising the innervation and blood supply of the muscles. ${ }^{15}$ The disadvantages of most techniques are the risk of developing a large ventral hernia, multiple operations, and the use of prosthetic materials. However, staged closure can carry the same risk as primary closure by placing the abdominal contents under pressure. ${ }^{3}$

\section{MATERIALS AND METHODS}

\section{Case Presentation}

A 13-year-old female presented at our hospital with a swelling over abdomen. The swelling was present since birth and gradually increased in size to attain the present size. No pain was associated with the swelling, only a dragging sensation throughout the day. The size of the swelling remained same during walking or lying down. The delivery was a normal vaginal delivery and there were no associated congenital anomalies. On examination, a 25 $\times 25 \mathrm{~cm}$ spherical-shaped swelling with no tenderness and soft in consistency and irreducible was found (Figs 1A to C). The liver could be palpated in the swelling. Abdominal cavity appeared to be empty. A defect could be felt in the rectus sheath above the umbilical ring. Contrast-enhanced computed tomography abdomen showed evidence of anterior abdominal wall defect measuring $6.5 \mathrm{~cm}$ at level of D12 to L3 vertebrae, with completely herniated liver, antrum, and pyloric canal of stomach with proximal part of duodenum s/o Exomphalos major. No evidence of any congenital anomalies.

\section{RESULTS}

The patient was operated upon and the sac was opened which contained the liver. The abdominal cavity had decreased capacity (Figs 2A and B). The CST technique was used to increase the capacity of abdominal cavity. This was done to prevent chances of abdominal compartment syndrome when the liver was repositioned in 

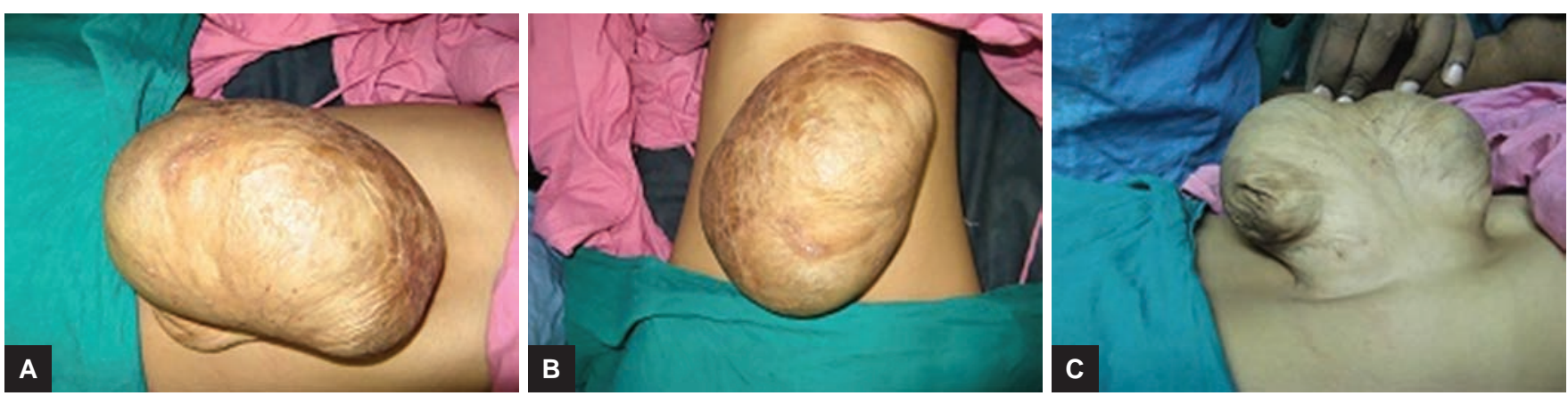

Figs 1A to C: (A) View of omphalocele from front; (B) horizontal view of omphalocele; and (C) view of omphalocele after retraction

the abdomen. Postoperative recovery was uneventful. Sutures were removed on 10th day. Regular follow-up was done. No evidence of any compartment syndrome or ventral hernia detected.

\section{DISCUSSION}

The management of $\mathrm{OC}$ aims to reintegrate the herniated viscera in the peritoneal cavity and to repair the anterior abdominal wall. This reinstatement must be done without abdominal compression. So it is necessary, after reinstatement of viscera into the abdomen and before abdominal wall repair, to check whether there is any cyanosis, respiratory, and circulatory disorders. ${ }^{2,6}$ The abdominal wall's closure with tension causes respiratory and circulatory disorders, intestinal necrosis, and infection, leading to death. ${ }^{2}$ Different delayed closure techniques are reported, but there are a number of advantages for using the CST. First, avoiding the use of foreign material results in lower infection rates and reduces the formation of dense adhesions. Especially in contaminated conditions, the CST is extremely useful. Second, the CST has the advantage of minimal advancing skin flaps and thus reducing the infection risk. Third, reconstruction of the normal anatomy of the abdominal wall is achieved and gives excellent functional and cosmetic results. Lastly, in most cases, it is a one-stage procedure. ${ }^{5}$ The CST is a promising technique for repairing giant OCs without the use of prosthetic material ${ }^{5}$ in neonates, which can be applied to adults as well.

\section{Surgical Technique ${ }^{16}$}

The CST is based on enlargement of the abdominal wall surface by translation of the muscular layers without compromising the innervation and blood supply of the muscles. The arterial blood supply of the abdominal skin is mainly via the intercostal arteries and the perforating branches of the epigastric artery and branches of the pudendal artery.

The patient lies in a supine position. After incision of the skin just lateral of the scar tissue on the OC, the abdominal cavity is entered. The liver and bowels are dissected free from the skin and ventral abdominal wall. In this manner, the lateral border of the rectus abdominal muscle can be identified properly from the interior of the abdomen (Fig. 3A). The skin and subcutaneous fat are dissected free from the anterior rectal sheath and the aponeurosis of the external oblique muscle, to 3 to $4 \mathrm{~cm}$ lateral of the rectus sheath (Fig. 3B). The aponeurosis of the external oblique muscle is incised approximately $1 \mathrm{~cm}$ of the lateral border of the rectus abdominis muscle (Fig. 3C). The aponeurosis
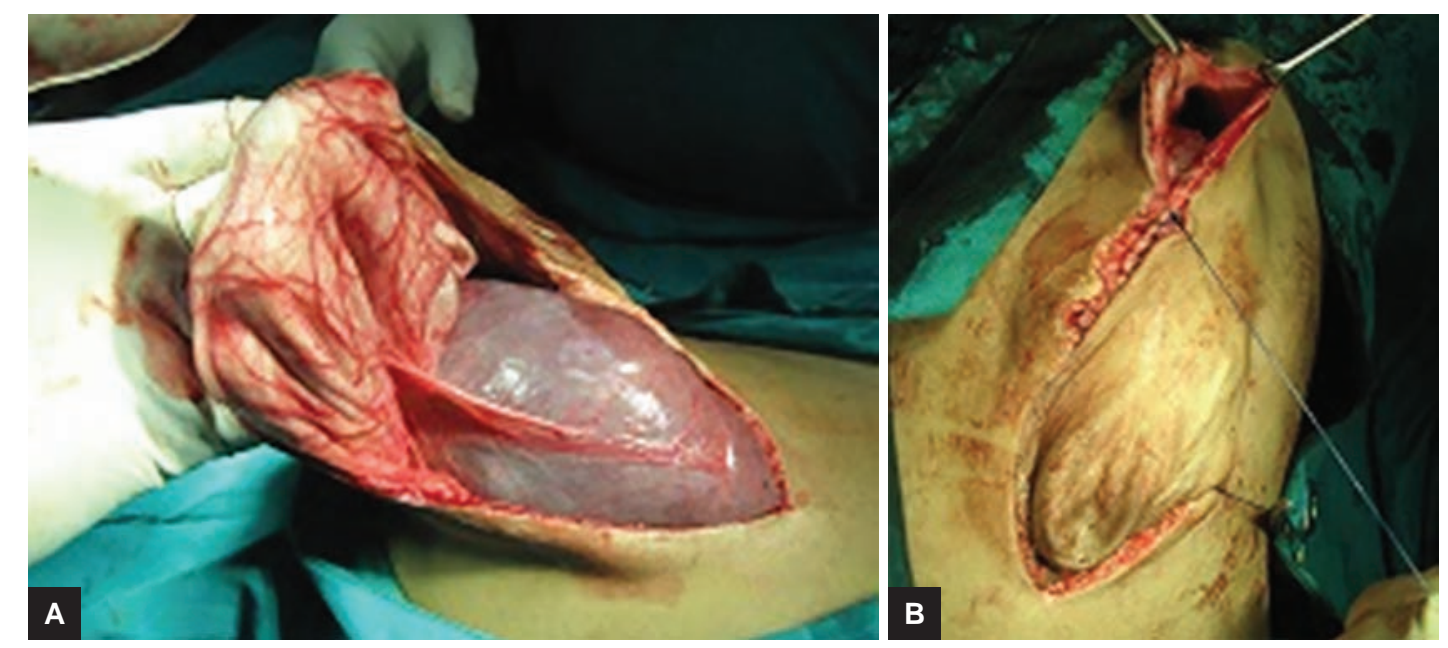

Figs 2A and B: (A) Opened sac showing liver; and (B) during closure 


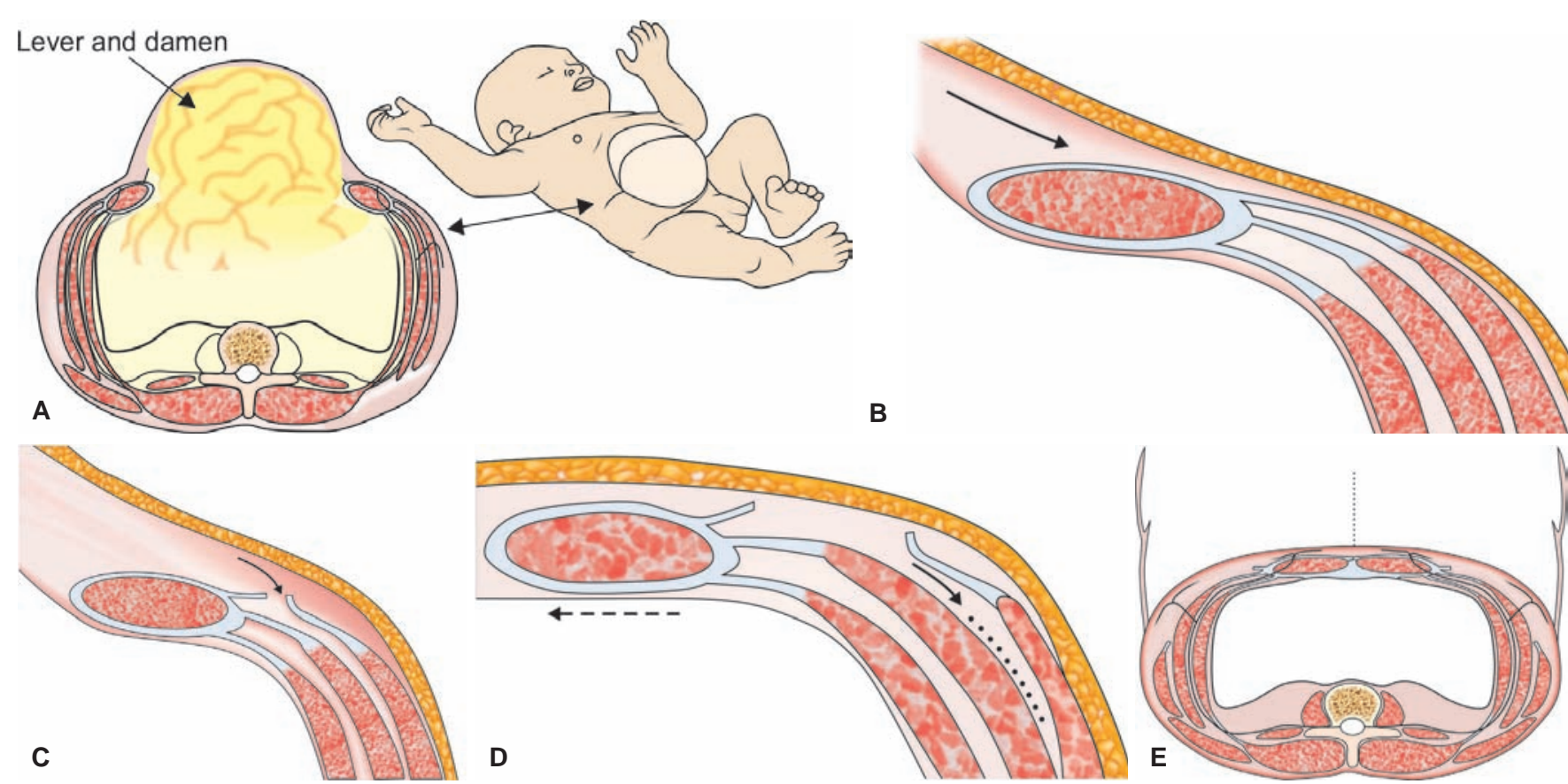

Figs 3A to E: The description of the CST in children with a giant OC: (A) A new born after epithelialization of the giant omphalocele; (B) dissection of the skin and subcutaneous fat from the abdominal wall muscles; (C) incision of the aponeurosis of the external oblique muscle $1 \mathrm{~cm}$ lateral of the rectus sheath; (D) separation of the external and internal oblique muscles; and (E) after closure of the abdomen, the external oblique muscle is retracted laterally

of the external oblique muscle is transected longitudinally over its full length. Transection includes the muscular part of the external oblique muscle on the thoracic wall. The attachment to the ribs must be dissected free to mobilize the rectus abdominis muscle to a maximum. Subsequently, the external oblique muscle is separated from the internal oblique muscle in the avascular plane between both muscles up to the mid-axillary line (Fig. 3D). Mobilization is essential because the fibrous interconnections between both muscles prevent optimal median shift of the rectus abdominal muscle. In this way, the rectus muscle can be shifted medially $5 \mathrm{~cm}$ at each side. The abdominal wall is closed in the midline with a running suture of a nonabsorbable or slowly absorbable suture material (PDS 2.0). The subcutis and skin are closed, and an umbilicus is created. After closure of the abdomen, the external oblique muscle is retracted laterally (Fig. 3E).

\section{CONCLUSION}

The management of giant OCs remains a challenge for pediatric surgeons. Although the mortality rate is still high (up to 20\%) in case of multiple congenital anomalies, surviving patients with $\mathrm{OC}$ achieve a state of health and quality of life comparable to that of general population peers. The newly introduced CST method seems to have a good outcome. The herniation rate is low, and prosthetic materials are not needed. ${ }^{5}$ Giant OC in an adult can be treated using the CST as in a neonate with favorable outcomes.

\section{REFERENCES}

1. Lee SL, Beyer TD, Kim SS, Waldhausen JH, Healey PJ, Sawin RS, Ledbetter DJ. Initial nonoperative management and delayed closure for treatment of giant omphaloceles. J Pediatr Surg 2006 Nov;41(11):1846-1849.

2. Pelizzo G, Maso G, Dell'Oste C, D'Ottavio G, Bussani R, Uxa F, Conoscenti G, Schleef J. Giant omphaloceles with a small abdominal defect: prenatal diagnosis and neonatal management. Ultrasound Obstet Gynecol 2005 Dec;26(7): 786-788.

3. Pereira RM, Tatsuo ES, Simoes E Silva AC, Guimarães JT, Paixão RM, Lanna JC, Miranda ME. New method of surgical delayed closure of giant omphaloceles: Lazaro da Silva's technique. J Pediatr Surg 2004 Jul;39(7):1111-1115.

4. Towne BH, Peters G, Chang JH. The problem of "giant" omphalocele. J Pediatr Surg 1980 Aug;15(4):543-548.

5. van Eijck FC, de Blaauw I, Bleichrodt RP, Rieu PN, van der Staak FH, Wijnen MH, Wijnen RM. Closure of giant omphaloceles by the abdominal wall component separation technique in infants. J Pediatr Surg 2008 Jan;43(1):246-250.

6. Allen RG, Wrenn EL, Jr. Silon as a sac in the treatment of omphalocele and gastroschisis. J Pediatr Surg 1969 Feb;4(1):3-8.

7. Bax NM, van der Zee DC, Pull ter Gunne AJ, Rövekamp MH. Treatment of giant omphalocele by enlargement of the abdominal cavity with a tissue expander. J Pediatr Surg 1993 Sep;28(9):1181-1184.

8. De Ugarte DA, Asch MJ, Hedrick MH, Atkinson JB. The use of tissue expanders in the closure of a giant omphalocele. J Pediatr Surg 2004 Apr;39(4):613-615.

9. Grob M. Conservative treatment of exomphalos. Arch Dis Child 1963 Apr;38:148-150.

10. Gross RE. A new method for surgical treatment of large omphalocele. Surgery 1948 Aug;24(2):277-283. 
11. Kapfer SA, Keshen TH. The use of human acellular dermis in the operative management of giant omphalocele. J Pediatr Surg 2006 Jan;41(1):216-220.

12. Pacilli M, Spitz L, Kiely EM, Curry J, Pierro A. Staged repair of giant omphalocele in the neonatal period. J Pediatr Surg 2005 May;40(5):785-788.

13. Schuster SR. A new method for the staged repair of large omphaloceles. Surg Gynecol Obstet 1967 Oct;125(4):837-850.

14. Zama M, Gallo S, Santecchia L, Bertozzi E, Zaccara A, Trucchi A, Nahom A, Bagolan P, De Stefano C. Early reconstruction of the abdominal wall in giant omphalocele. Br J Plast Surg 2004 Dec;57(8):749-753.

15. Ramirez OM, Ruas E, Dellon AL. "Components separation" method for closure of abdominal-wall defects: an anatomic and clinical study. Plast Reconstr Surg 1990 Sep;86(3): 519-526.

16. Bleichrodt RP, deVries Reilingh TS, Malyar A, van Goor H, Hansson B, van der Kolk B. Component separation technique to repair large midline hernias. Oper Techn Gen Surg 2004 Sep;6(3):179-188. 